
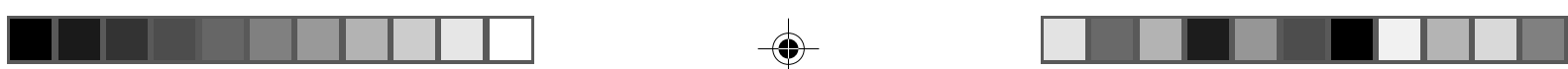

\title{
Os japoneses na Amazônia e sua contribuição ao desenvolvimento agrícola
}

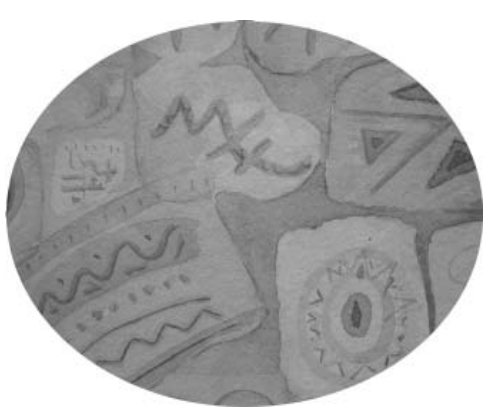

Alfredo Kingo Oyama Homma, D.S. *

\section{Resumo}

A imigração japonesa na Amazônia foi iniciada 21 anos depois da vinda dos primeiros imigrantes do Kasato Maru, cujo centenário foi comemorado em 18 de junho de 1908. Os primeiros colonos vieram para Tomé-Açu (1929), no Estado do Pará e, em Maués (1930) e Parintins (1931), no Estado do Amazonas. Na época em que foi iniciada a imigração japonesa na Amazônia, a economia regional era essencialmente extrativista e em estagnação, devido à crise da borracha, que chegou a participar como terceiro produto de exportação do País. O sucesso da colonização japonesa decorreu do modelo baseado na introdução de recursos da biodiversidade exógena, numa época em que era um comportamento normal. Recursos genéticos da Amazônia eram levados para outras partes do País e do mundo e por sua vez os migrantes trouxeram de outros locais para a região. O novo enfoque de desenvolvimento induzido pelos descendentes dos japoneses está baseado no aproveitamento da biodiversidade local associado com plantas exóticas introduzidas no passado e outras mais recentes de forma clandestina. O Japão poderia ajudar muito a Amazônia, mediante convênios técnico-científicos que sejam complementares, na recuperação das áreas degradadas e da fauna pesqueira, controle da poluição dos rios, tecnologia de madeira, aproveitamento dos recursos da biodiversidade na área de cosméticos, fármacos, corantes naturais, entre os principais. Quanto às exportações há necessida-

\footnotetext{
Economista Agrícola, Embrapa Amazônia Oriental, Caixa Postal, 48, CEP 66095-100, Belém, Pará. E-mail: homma@cpatu.embrapa.br, Contato: (91) 3204-1082.

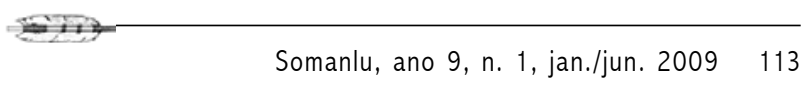


de de equilibrar a balança comercial dos Estados do Amazonas, Pará e Maranhão com o Japão, desfavorecida pelas importações da Zona Franca de Manaus e dos baixos preços dos produtos da natureza que são exportados.

Palavras-chave: Imigração japonesa. Amazônia. Desenvolvimento agrícola. Juta,. Pimenta-do-reino.

\section{Abstract}

The japanese immigration in the Amazon started 21 years after the Kasato Maru ship brought the first immigrants to São Paulo, on june 18, 1908. The first colonists came for Tomé-Açu (1929), in the state of Pará and, in Maués (1930) and Parintins (1931), in the state of Amazonas. At the time that the japanese immigration started in the Amazon, the regional economy was essentially extrativist and in stagnation, due to the rubber crisis, which, some years before, was the third exportation product of Brazil. The success of the Japanese colonization rested on a model based on the introduction of resources from the exotic biodiversity, in a time when this was a normal behavior. Genetic resources of the Amazon were taken to other parts of the country and of the world and, in turn, the migrants brought exogenous genetic resources to their new land. The new development focus induced by the descendants of the japanese is based on the use of the local biodiversity associated with exotic plants introduced in the past and other more recent in an obscure way. Japan could substantially help the Amazon by the means of technical-scientific agreements that are complementary in the reclamation of degraded areas and of fishing areas, control of pollution of rivers, lumber technology and the use of biodiversity resources in the cosmetic related areas, pharmaceutical products and natural dyes, among others. In relation to exportation, there is the need to equilibrate the trade balance of the states of Amazonas, Para and Maranhão with Japan, hindered by the imports of the Manaus Free Zone and by the low prices of natural products that are exported.

Keywords: Japanese immigration. Amazon. Agricultural development. Jute. Black pepper.

114 Somanlu, ano 9, n. 1, jan./jun. 2009 


\section{Introdução}

A imigração japonesa na Amazônia foi iniciada 21 anos depois da vinda dos primeiros imigrantes do Kasato Maru, cujo centenário foi comemorado em 18 de junho de 2008. Os primeiros colonos vieram para Tomé-Açu (1929), no Estado do Pará e, em Maués (1930) e Parintins (1931), no Estado do Amazonas. Para o esforço da imigração japonesa na Amazônia destacam-se os esforços de Hachiro Fukuhara (1874-1943) e Sanji Muto (1867-1934), no Estado do Pará e Tsukasa Uyetsuka (18901978) no Estado do Amazonas e Kotaro Tsuji (1903-1970) na imigração do pósguerra (HOMMA, 2007).

Na época em que foi iniciada a imigração japonesa na Amazônia, a economia regional era essencialmente extrativista e em estagnação, devido à crise da borracha provocada pela biopirataria de um produto ativo da economia, cujas sementes de seringueira foram levadas por Henry Alexander Wickham (1846-1928), em 1876, para o Sudeste asiático. A borracha chegou a participar como terceiro produto de exportação do país vindo logo depois do café e do algodão. Rio de Janeiro era a capital do Brasil que permaneceria até 1960, quando foi transferida para Brasília. O extrativismo da borracha tinha também destruído a incipiente agricultura colonial que existia na região amazônica pela drenagem de mão de obra para os seringais.

Quando a imigração japonesa foi iniciada na Amazônia ainda prevalecia a saga do imaginário amazônico, que servira de relato a diversos exploradores, cientistas e escritores. Em 1800, o barão alemão Friedrich Wilhelm Karl Heinrich Alexander von Humboldt (1769-1859) alcunharia a Amazônia como sendo o "celeiro do mundo", que iria contrapor a do pernambucano Alberto Rangel (1871-1945), de "Inferno Verde", em 1904; do clássico "A Selva”, do escritor português José Maria Ferreira de Castro (1898-1974) em 1930 e da "Amazônia Misteriosa", do carioca Gastão Cruls (1888-1959), em 1935. A Amazônia era uma região desconhecida pelos próprios brasileiros, da qual os relatos dos viajantes constituíam a literatura científica existente e com acesso muito limitado (HOMMA, 2003).

Hoje, com as facilidades do celular, aviões a jato e internet, a Amazônia se tornou um espaço virtual, cujos acontecimentos, são conhecidos imediatamente no mundo inteiro. A primeira ligação telegráfica ligando Belém ao Sul do país foi efetuada em 1873 e somente em 1896, Manaus foi conectada com Belém. 
A visão "nipocêntrica", de valorizar as dificuldades do meio ambiente que os imigrantes japoneses enfrentaram no Brasil, tem sido a tônica da maioria dos textos que descrevem a imigração no país, perde o seu sentido, uma vez que os habitantes regionais vivem em completa harmonia com a natureza e a tragédia e a perda da condição humana, tem sido mais trágica para os próprios migrantes brasileiros na Amazônia, mesmo na época contemporânea.

A Amazônia, até a década de 1950, era uma "civilização das várzeas", que dependia do transporte fluvial, das cidades alinhadas ao longo da calha dos principais rios navegáveis, cujas cidades lembravam as cidades portuguesas. A ocupação de terra firme restringia a periferia dos principais núcleos urbanos. Este modelo de ocupação seria quebrada em 1960, com a abertura da rodovia Belém-Brasília, quando a "civilização da várzea" muda para a "civilização de terra firme", passando a se estabelecer ao longo das estradas que começaram a rasgar a Amazônia em todos os sentidos. Entre estes dois extremos, ocorreu a construção de três estradas de ferro: a Estrada de Ferro Tucuruí para vencer o trecho encachoeirado do rio Tocantins (1908-1944), a mais importante ligando Belém a Bragança (1883-1908) e a Madeira-Mamoré (19071912), constituíam três riscos que existiam nos mapas da Amazônia no início do século XIX. Hoje as estradas abertas na Amazônia somam mais de 240 mil quilômetros, equivalente a seis voltas ao redor do planeta (HOMMA, 2003).

Com a civilização da terra firme que passou a constituir no modelo de ocupação predominante, os portos e as estações ferroviárias perderam a importância sendo substituídas pelas estações rodoviárias, na busca de sonhos e esperanças e tragédias. A imigração em Parintins era apoiada na ocupação das áreas de várzeas e no transporte fluvial enquanto em Tomé-Açu, a ocupação era nas terras firmes e até 1973, dependente do transporte fluvial.

No cenário político, quando foi iniciada a imigração japonesa na Amazônia, os governos ditatoriais ensaiavam o domínio no mundo: Adolf Hitler (1889-1945) governou a Alemanha no período de 1933 a 1945, Benito Mussolini (1883-1945) governou a Itália no período 1922 a 1943 e, no Japão, o militarismo simbolizado no general Hideki Tojo (1884-1948) governou no período 1941 a 1944, formavam o Eixo, que teve grandes consequências negativas nos destinos da humanidade. Na URSS, Joseph Stalin (1879-1953) governou com mão de ferro durante o período 1922 a 1953; na Espanha, o general Francisco Franco (1892-1975) dirigiu o país no período 1939 a 1973 e, em Portugal, Antônio de Oliveira Salazar (1889-1970) conduziu o

116 Somanlu, ano 9, n. 1, jan./jun. 2009 


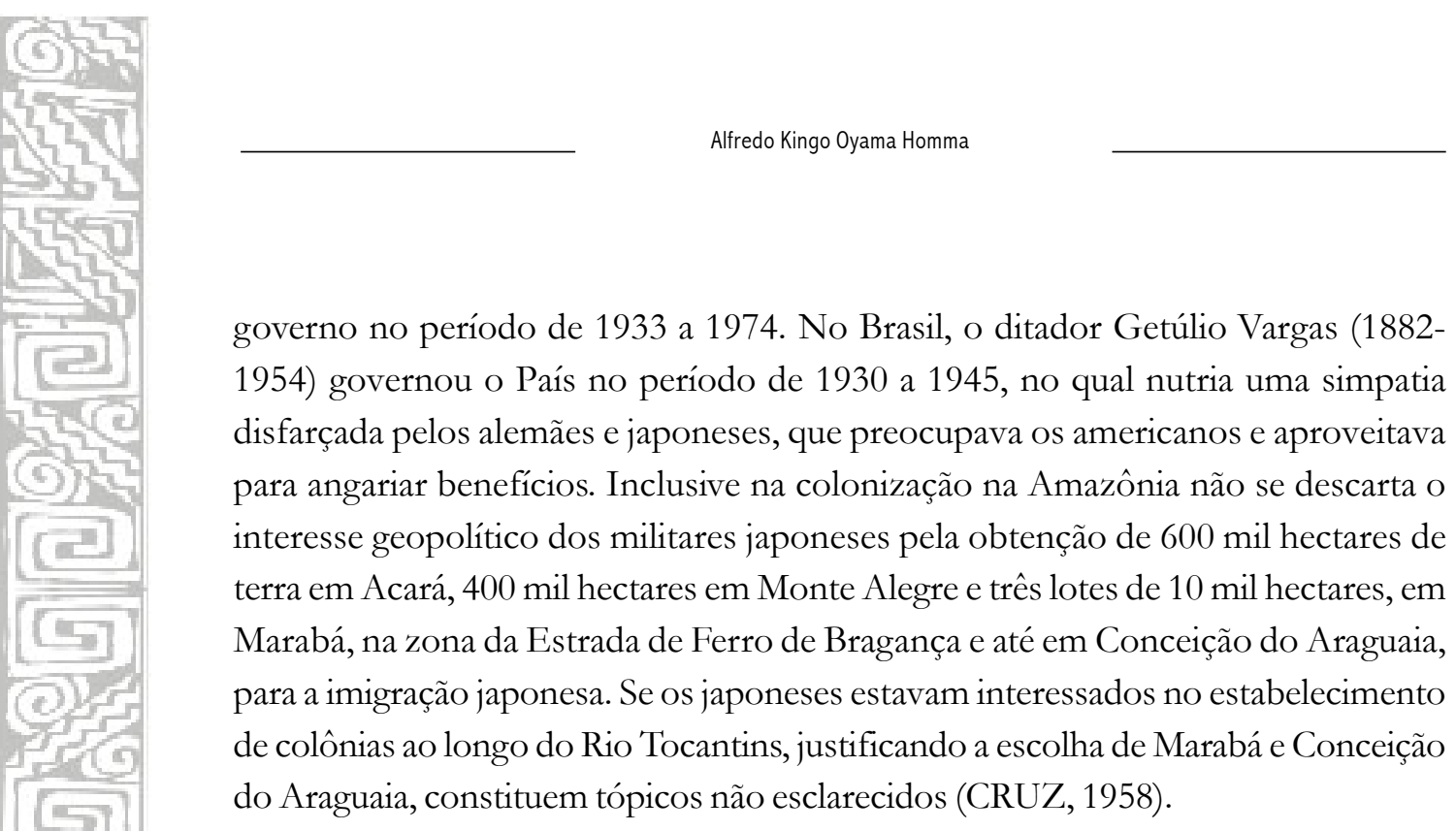

\section{A agricultura na Amazônia antes da imigração japonesa}

O sucesso da transferência de sementes de seringueiras por Henry Alexander Wickham, em 1876, para o Sudeste asiático fez com que, em 1913, a produção de borracha fosse igual a da região amazônica. Foi o maior sucesso de domesticação na época contemporânea. Em 1908, a produção da borracha amazônica representava $94,4 \%$ da produção mundial e dez anos depois, em 1918, apenas 10,9\%. Foi a maior crise econômica, social e política que a região amazônica sofreu, com a biopirataria de um produto ativo da economia. O extrativismo da seringueira foi responsável pelo processo de povoamento dos altos rios, da anexação do Acre (1903) à soberania nacional antes pertencente à Bolívia e da geração de riquezas transferidas para o Sul do País, dos gastos supérfluos e da construção de diversas pirâmides, como o Teatro da Paz (1878) e o Teatro do Amazonas (1896), entre outros palácios e prédios e obras de infraestrutura como o Porto Flutuante de Manaus (1902), Estrada de Ferro Bragança (1908), a Estrada Madeira-Mamoré (1912), entre outros.

Contudo, antes do ciclo da borracha, outro ciclo importante foi a do extrativismo e a semidomesticação do cacau nas áreas de várzeas dos Estados do Pará e Amazonas. As exportações de cacau chegaram a representar mais de $90 \%$ do valor das exportações e perdurou até a época da Independência do Brasil em 1822. A perda da importância do cacau foi decorrente da transferência do cacaueiro para a Bahia, efetuada em 1746, por Louis Frederic Warneaux, para a fazenda de Antônio Dias Ribeiro, no município de Canavieiras, iniciando a expansão dos plantios racionais, a Amazônia perderá a competitividade. É interessante realçar que da Bahia o 
cacaueiro foi levado para a África Ocidental e para o Sudeste asiático, transformando em importantes culturas nesses novos locais (HOMMA, 1989).

Com a crise da borracha, a população da Amazônia ficou estagnada no período de 1920 a 1940, quando outros produtos extrativos tentaram ocupar o seu espaço, como a da extração do óleo essencial de pau-rosa e da castanha-do-pará, mas nunca conseguiram recuperar a primazia da borracha.

Foi nesse cenário que foi iniciado a imigração japonesa na Amazônia, onde se buscava novas alternativas econômicas, decorrente da crise da borracha. Dessa forma os governantes da época nutriam grandes esperanças com o empreendimento da Ford Motor Company, iniciado em 1927, nas margens do rio Tapajós, e o início da imigração japonesa em 1929, onde não se observava nenhum sentido xenófobo.

\section{0 modelo de desenvolvimento baseado na transferência de recursos genéticos}

O desenvolvimento das atividades agrícolas no Brasil foi decorrente de forte transferência de recursos genéticos provenientes de outras regiões do mundo que foram trazidas pelos colonizadores portugueses. De forma idêntica, diversos produtos, do Novo Mundo e da Amazônia, foram transferidos para outras partes do País e do mundo, transformando em importantes atividades econômicas nestes novos locais (HOMMA, 2003).

A principal riqueza agrícola do País, o café, foi introduzida por Francisco de Melo Palheta (1670 - ?), em 1727, no Estado do Pará, proveniente de Caiena. O próprio brasão da República Federativa do Brasil tem um ramo de cafeeiro e outro de fumo, uma planta exótica e um vício. O primeiro rebanho bovino foi introduzido em 1534, por Ana Pimentel, esposa de Martin Afonso de Souza (1490-1564), em São Paulo, tornando o Brasil com um rebanho superior a 207 milhões de cabeças, no maior exportador de carne bovina e no maior rebanho do planeta. O búfalo, que se tornou no símbolo da ilha de Marajó, foi introduzido por Vicente Chermont de Miranda (18491907), efetivado em 1882, de matrizes provenientes da Guiana Francesa.

A posição destacada do Brasil como maior exportador de suco de laranja e como segundo maior produtor e maior exportador de soja do mundo decorre de duas plantas que têm sua origem na China. A banana, que tem sido o símbolo da

118 Somanlu, ano 9, n. 1, jan./jun. 2009 


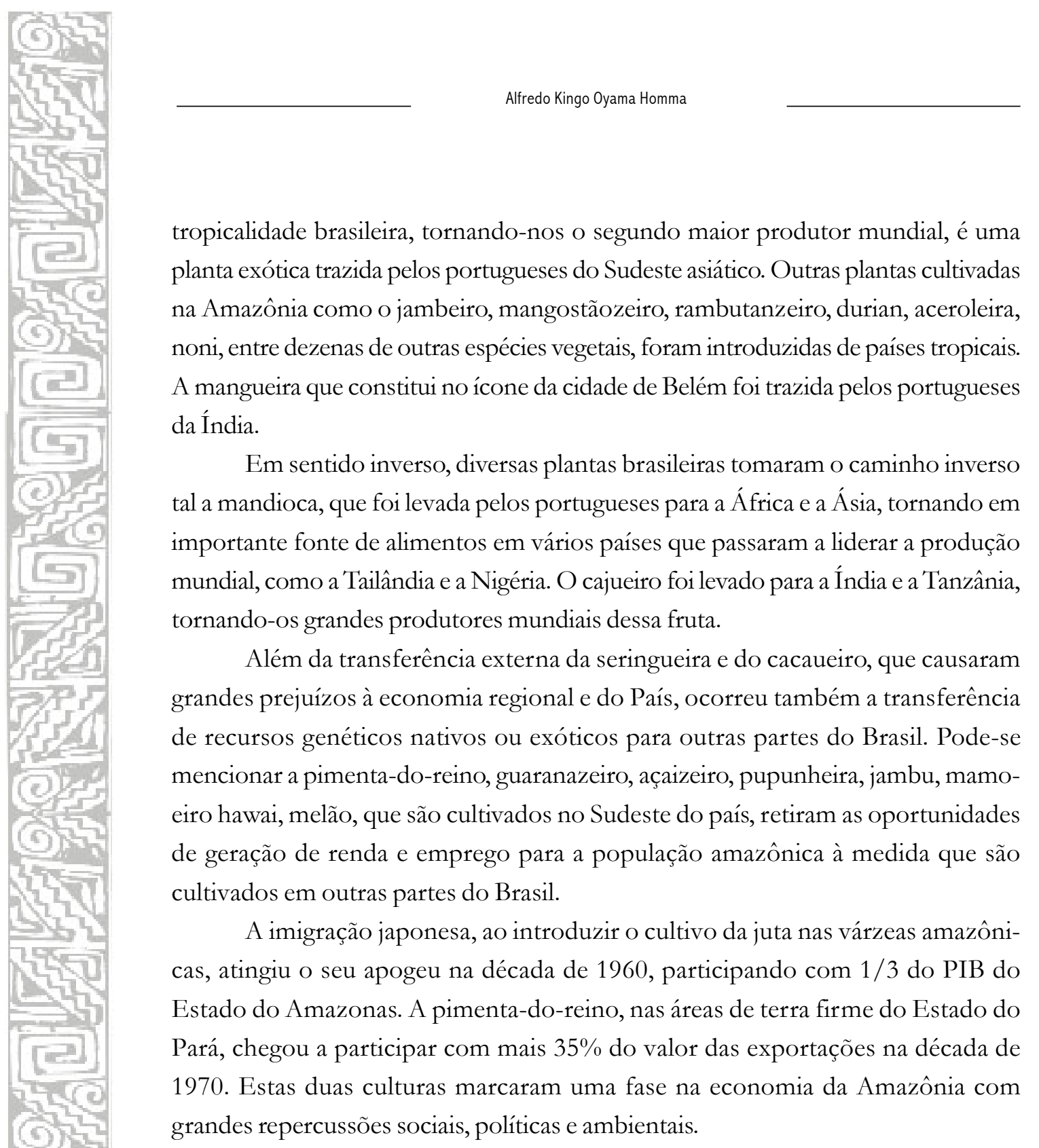

\subsection{Razões do sucesso das lavouras de juta e pimenta-do-reino}

O sucesso da lavoura da juta não teria sido possível se não tivesse ocorrido a II Guerra Mundial, ao impossibilitar a importação de fibra de juta indiana, pela inexistência de transporte marítimo. Os industriais paulistas não creditavam grande confiança no sucesso da juticultura nas várzeas amazônicas em suprir a demanda de sacaria para os produtos agrícolas, sobretudo para a exportação de café.

Somanlu, ano 9, n. 1, jan./jun. 2009119 
Outra razão decorreu da existência de mão de obra liberada com a crise da borracha que, decorrente dos baixos preços da borracha e da inexistência de mercado, passou a viver da caça, pesca e da reduzida agricultura de subsistência ao longo das várzeas.

Com a facilidade de multiplicação das sementes de juta, após o desânimo de muitos colonos japoneses, houve a decisão de Ryota Oyama (1882-1972) de levar adiante o salvamento de dois pés de juta, apesar do descrédito geral, foi que levou à criação do ciclo da juta. Se a juta fosse uma planta com poucas sementes o sucesso não teria sido possível. Posteriormente, com o sucesso muitos passaram a afirmar como sendo aclimatadores de juta ou tentaram defender o aspecto institucional, contando a história como se fosse um evento conhecido, em uma justificativa burocrática, de frente para trás (HOMMA, 2007).

No caso da lavoura da pimenta-do-reino, de forma idêntica, a decisão de trazer as mudas por Makinossuke Ussui (1894-1993) e, depois cultivar para manter as mudas efetuadas por Tomoji Kato (1898-1956) e Enji Saito (1891-1958). A pimentado-reino tinha pouco valor econômico na época e sem previsão futura, para que somente duas décadas depois, tornar-se um recurso econômico, cabe o mérito do sucesso à lavoura de pimenta-do-reino.

A falta de resultados de pesquisa locais que resultou no fracasso do plantio de seringueira da Ford Motor Company, iniciado em 1927 e encerrado em 1945, foi também a razão do sucesso das atividades de imigração japonesa na Amazônia e no País. O conhecimento e a experiência agrícola dos imigrantes japoneses na época suplantavam a da agricultura de derruba e queima que era praticada no Brasil, da falta de mão de obra e da aversão do trabalho manual, decorrente do resquício da escravidão. A pesquisa agrícola brasileira se concentrava em poucas instituições como o Instituto Agronômico de Campinas (1887), nas Escolas de Agronomia, entre elas a de Pelotas (1883), Cruz das Almas (1887), Piracicaba (1898), Lavras (1908) e Viçosa (1927). É interessante mencionar que na região amazônica chegou a funcionar a Escola Agronômica de Manaus fundada em 1912 e fechada em 1943 e, em Belém, da Escola de Agronomia do Pará que funcionou no período 1918-1941 (TUFFANI, 2009). A chegada dos imigrantes japoneses trazendo novas ideias e culturas permitiram que se criassem novas atividades e de substituição de importações.

120 Somanlu, ano 9, n. 1, jan./jun. 2009 


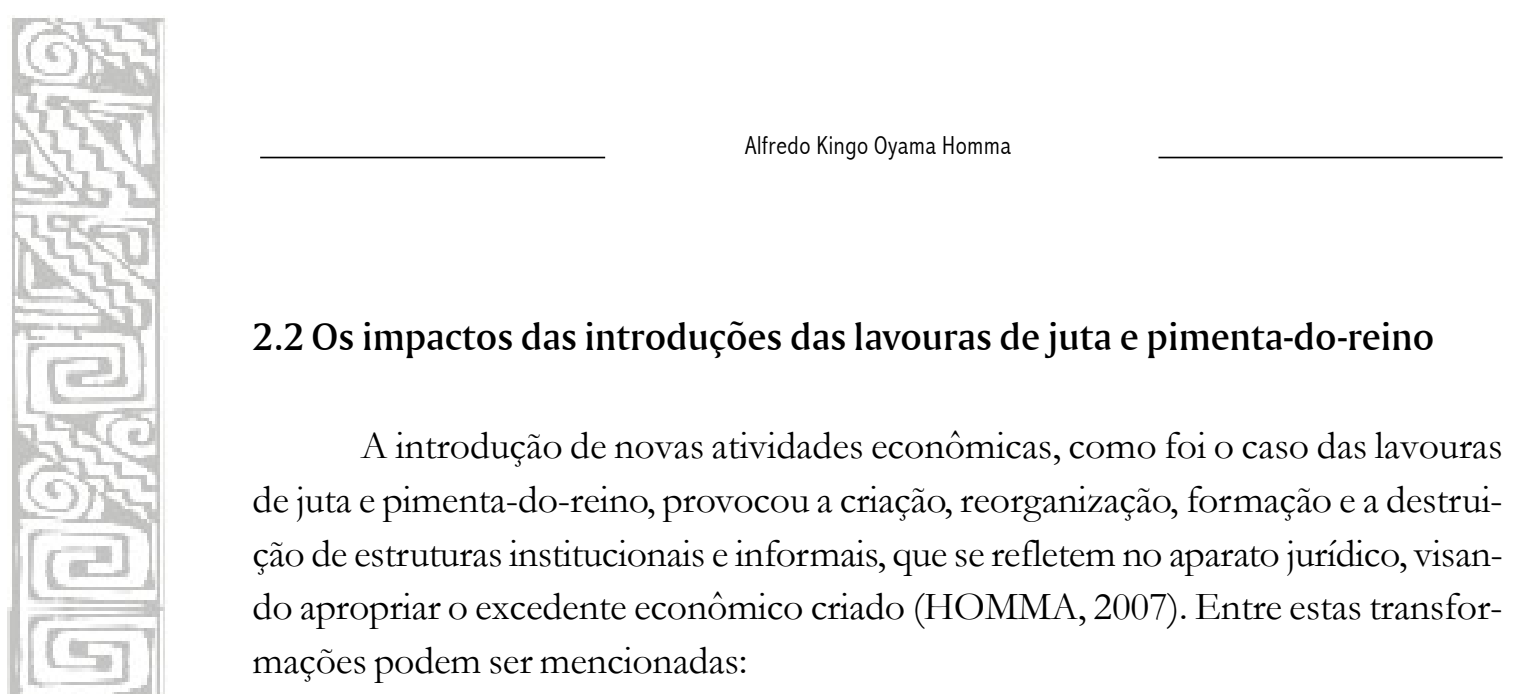

\subsection{Impactos socioeconômicos}

A lavoura da pimenta do reino iniciou a agricultura de NPK e da mecanização na Amazônia, antes baseada somente nas cinzas das queimadas, criando um mercado de venda de insumos agrícolas. Antes atividade inerente dos agricultores japoneses, com o tempo, os trabalhadores braçais passaram a dominar as técnicas de cultivo e desenvolver plantios próprios ou trabalhando como empregados de agricultores brasileiros, ligados às mais diferentes atividades profissionais, entre os quais, médicos, advogados, políticos, etc.

Dessa forma, com a lavoura da pimenta do reino, a partir da década de 1970, começa o processo de mimetismo pelos agricultores brasileiros, nas áreas de terra firme, ao longo das estradas existentes, da imitação das atividades dos agricultores japoneses. Isso demonstrou que os agricultores brasileiros não são avessos a inovações, mas reagindo positivamente quando sinais de preços e de mercado são favoráveis.

Trata-se de uma atividade altamente intensiva em mão de obra necessária para tratos culturais e, sobretudo, por ocasião da colheita, com envolvimento de homens, mulheres e crianças. Numa época em que a legislação trabalhista não fazia nenhuma cobrança com relação ao emprego de mão-de-obra infantil e de mulheres, a colheita de pimenta-do-reino era uma oportunidade de auferir renda familiar extra, onde passavam o dia inteiro nos pimentais. As feiras nos finais de semana e o comércio nas localidades onde a pimenta-do-reino se expandia notava-se a circulação de dinheiro. Formou-se, também, uma complexa rede de compradores de pimenta do reino, prepostos de exportadores, com demarcação de espaços informais e controle de preços, bem como na venda de insumos como adubos orgânicos e químicos e de maquinaria utilizada nos pimentais. 
Quanto à lavoura da juta, a rede de aviamento existente no tempo dos seringais foi rapidamente adaptada para atender o complexo da produção de fibra de juta, com a instalação de prensas e de compradores de fibra e do adiantamento de crédito em forma de ferramentas e gêneros de primeira necessidade. O primeiro processo de agroindustrialização na Amazônia foi iniciado com o beneficiamento da fibra de juta com a instalação de fábricas de fiação e tecelagem em Castanhal, Belém, Santarém e Manaus. No interregno entre a crise da borracha (década de 1910) e a instalação da Zona Franca de Manaus (1967), foi a lavoura da juta que garantiu o sustentáculo da economia do Estado do Amazonas.

A dificuldade inicial para a expansão dos plantios de juta decorreu da oferta de sementes, onde os próprios agricultores japoneses reservavam uma área para a produção de sementes. Era frequente o roubo de sementes de juta daqueles que produziam sementes tanto de japoneses e de agricultores brasileiros. A Associação Comercial do Amazonas tomou a responsabilidade da produção de sementes de juta em 1940, até ser implantado um centro de produção de sementes em terra firme no Município de Alenquer, no Estado do Pará, pelo Instituto Agronômico do Norte, viabilizando a produção de sementes de juta com o plantio de milho no período 1948 a 1965. A expansão desses plantios provocou considerável desmatamento em áreas de terra firme com ocorrência de castanheiras.

\subsubsection{Impactos ambientais}

As várzeas são faixas estreitas que acompanham o curso do rio Amazonas e de seus afluentes, sujeitos a inundações anuais. Em decorrência dessas inundações são solos de elevada fertilidade, que representam $6 \%$ da superfície da Amazônia Legal. A lavoura da juta, ao se tornar uma atividade econômica, provocou o desmatamento das florestas de várzeas, permitindo o cultivo por duas a três safras e o consequente abandono, pelo praguejamento com ervas daninhas ou o seu retorno depois de cinco a dez anos com a recuperação parcial da vegetação primitiva. Muitas dessas áreas foram ocupadas pela pecuária que se acentuou com a decadência da juta. Uma das limitações da lavoura de juta era a sua dependência de sementes que eram produzidas nas áreas de terra firme no Município de Alenquer, mediante desmatamento de floresta densa. A defasagem entre a época de colheita de sementes de juta e o plantio mais cedo no Estado do Amazonas era motivo de constantes conflitos entre o gover-

122 Somanlu, ano 9, n. 1, jan./jun. 2009 


\subsubsection{Impactos políticos}

A influência política das atividades produtivas introduzidas pelos imigrantes japoneses se fez sentir na criação de legislações específicas para os diversos produtos que passaram a ser desenvolvidos. Estas legislações, além de estabelecerem padrões normativos, dando vida jurídica para as atividades produtivas, fazem parte do controle capitalista visando apropriar o excedente do processo produtivo.

A presença de descendentes de japoneses na vida política da região amazônica se faz sentir na ocupação de cargos de secretários de Estado, como de Agricultura, Indústria e Comércio, deputado estadual, presidentes de estatais estaduais e federais sediadas nos Estados, prefeitos e vereadores dos municípios, principalmente nos locais onde se destaca a presença de agricultores nipo-brasileiros.

Somanlu, ano 9, n. 1, jan./jun. 2009123 
Em Manaus, decorrente da implantação da Zona Franca de Manaus, ocorreu uma grande afluência de empresários japoneses e dos países desenvolvidos e com isso modificou drasticamente o comportamento do empresariado local e das autoridades públicas daquele Estado. Enquanto na maioria dos Estados da Amazônia Legal predomina o clientelismo e o apanágio a dependência do Estado e o culto ao atraso, em Manaus, verifica-se uma agressividade empresarial mais forte. Noutros Estados como o Pará e o Maranhão, apesar da presença de capitais e executivos estrangeiros no setor mínero-metalúrgico, não há reflexos positivos com relação a essas mudanças no processo administrativo.

Verifica-se a forte presença de descendentes de japoneses, ocupando profissões liberais, seja na esfera pública federal, estadual ou municipal ou na iniciativa privada. Descendentes de japoneses são cientistas da Embrapa, Museu Paraense Emílio Goeldi, Instituto Nacional de Pesquisas da Amazônia, professores das universidades federais, estaduais e privadas, funcionários de órgãos federais, estaduais e municipais, advogados, médicos, odontólogos, engenheiros, etc. Alguns se tornaram grandes empresários no setor de construção civil, comércio, exportação, etc.

\section{A perda da importância das lavouras de juta e pimenta-do-reino}

A lavoura da juta, por ser altamente intensiva em mão de obra, uma cultura anual, pelas condições inóspitas de trabalho, a premência de corte com a subida das águas e a impossibilidade de mecanização, dificultou a sua expansão em larga escala pelos agricultores japoneses. Estes foram gradativamente abandonando o plantio de juta, pela perda da rentabilidade, passando para os ribeirinhos e mudando-se para outros locais e atividades mais rentáveis. A falta de mão de obra para efetuar a coleta de produtos extrativos e mais tarde no desenvolvimento das atividades agrícolas sempre foi um fator restritivo na Amazônia, que só seria quebrado a partir da década de 1970, com a abertura de grandes eixos rodoviários. (HOMMA, 1989).

A criação da Suframa, em 1967, promoveu forte migração rural urbana do Estado do Amazonas com inchamento da cidade de Manaus, abandonando as atividades agrícolas das várzeas com consequente reflexo na queda da produção de fibra de juta. A falta de sementes de juta constituía um problema crônico, que levou à entrada do cultivo da malva, a partir de 1971, nas várzeas do Estado do Amazonas, mas que não refletiu na melhoria da lucratividade.

124 Somanlu, ano 9, n. 1, jan./jun. 2009 


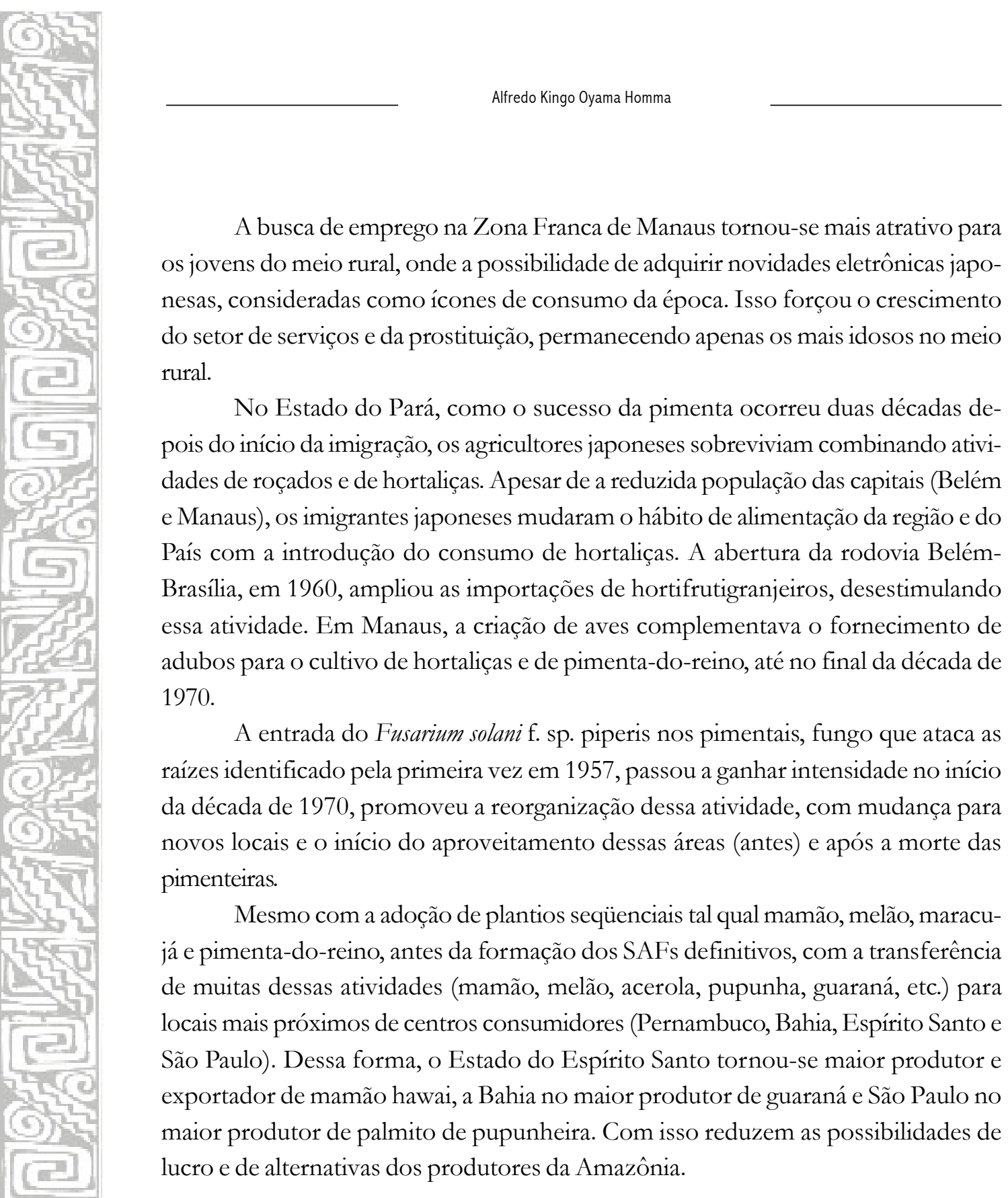

5 A nova realidade agrícola e a contribuição da imigração japonesa na Amazônia

A entrada do Fusarium promoveu a mudança dos sistemas produtivos baseados no monocultivo da pimenta-do-reino e com a formação de sistemas agroflorestais tendo o cacaueiro como principal cultura base. A premonição do crescimento da 
importância do cupuaçuzeiro foi pressentida no início da década de 1980 com o plantio pioneiro de Katsutoshi Watanabe em Tomé-Açu. A eclosão da questão ambiental, cujo ápice ocorreu com o assassinato de Chico Mendes em 22/12/ 1988, promoveu a divulgação das frutas amazônicas na mídia nacional e internacional, com ampliação do consumo (HOMMA, 2003).

Dessa forma, as frutas regionais que antes tinham um consumo local e, na época da safra, passaram a ser exportados para outras partes do País e do exterior e com o processo de beneficiamento da polpa passaram a ser consumidos durante o ano. Com isso provocou a elevação dos preços e, no caso do açaí, a exclusão de um produto alimentar das camadas mais pobres da população regional.

O grande crescimento da agricultura nacional, que começa a se evidenciar a partir da década de 1970 e o desenvolvimento da pesquisa agrícola nacional nas universidades, instituições de pesquisa locais e a criação da Embrapa, em 1973, reduziu o valor e a importância dos agricultores descendentes de japoneses na oferta de novidades para o setor agrícola. As novidades estão concentradas em determinados segmentos de horticultura, avicultura e fruticultura de clima temperado.

O interesse do governo japonês pela expansão do cultivo da soja, arroz e milho nos cerrados, que representa 207 milhões de hectares ou $24 \%$ do território nacional, está relacionado com as consequências das políticas internacionais e de garantir a segurança alimentar. Em 1974, durante o governo Geisel (1974-1978), foi assinado acordo com o governo japonês para a implantação do Programa NipoBrasileiro de Cooperação para o Desenvolvimento Agrícola da Região do Cerrado (Prodecer). O ministro da Agricultura Allyson Paulinelli (1936) teve destacado papel na condução inicial do programa considerado o maior projeto agrícola do país na época, resultou na mudança da agricultura litorânea para o centro do país. Isso resultou numa joint venture, a Companhia de Promoção Agrícola (Campo), resultante da união da empresa brasileira Companhia Brasileira de Participação Agrícola (Brasagro) que detinha 51\% do capital e da japonesa Japan-Brazil Agricultural Development Corporation (Jadeco), ficou com 49\%. Entre as 24 empresas que formaram a Brasagro na época estão: o Banco do Brasil, Bamerindus, Banco Econômico, Banco Nacional, Cica Norte, Manah, Eucatex, Solorrico, Brahma, Florestal Acesita, Nutricia, CVRD. Já na holding japonesa tinha 48 empresas, destacando-se entre elas a Mitsubishi, o Bank of Tokyo, a Central das Cooperativas do Japão, a Mitsui, a Ishikawagima, a Toshiba e principalmente a Japan Internacional

126 Somanlu, ano 9, n. 1, jan./jun. 2009 


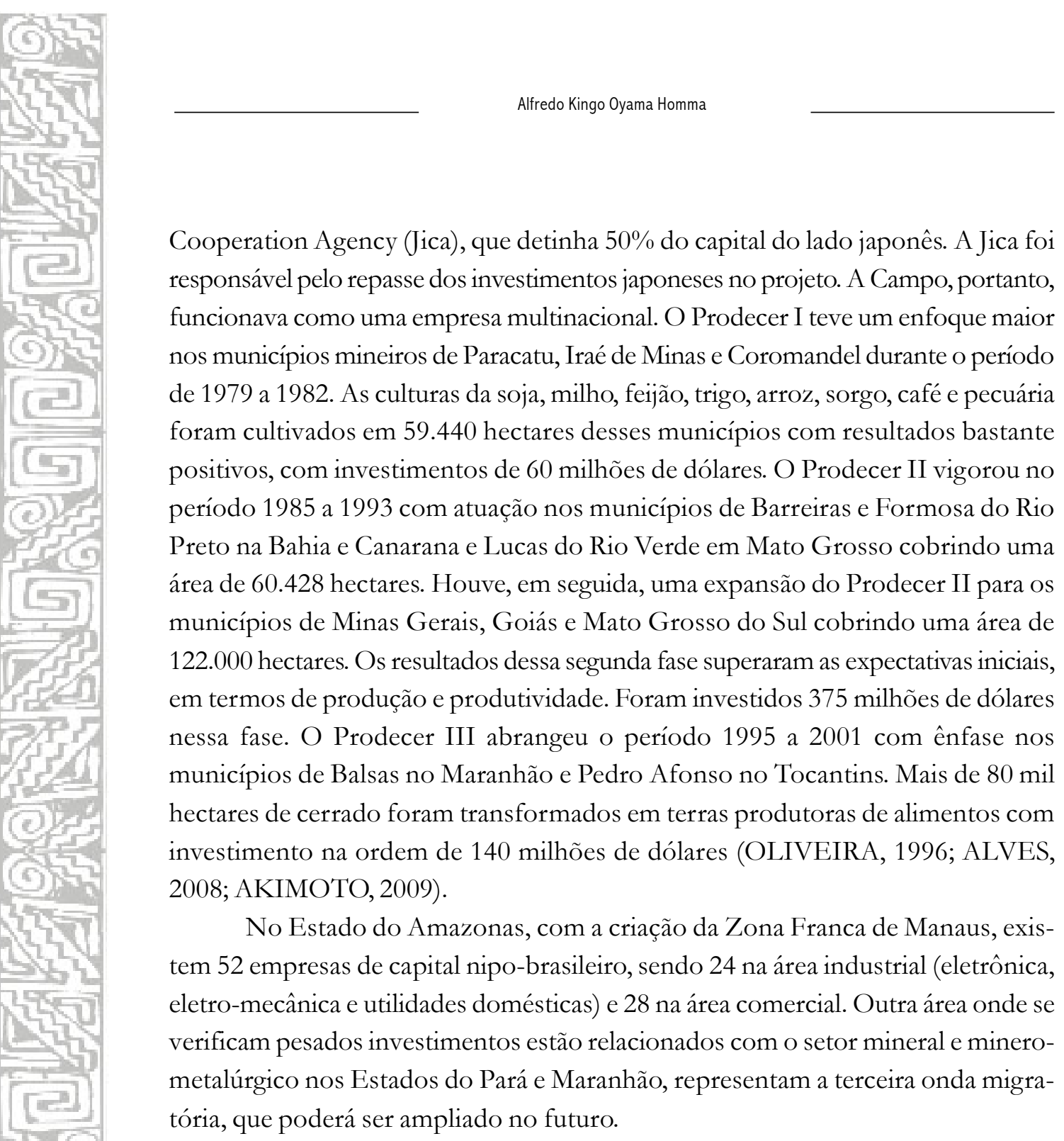

\section{Caminhos para cooperação nipo-brasileira na Amazônia}

Antes do centenário da imigração japonesa, três grandes ícones que eram tidos como sinônimos da eficiência, perseverança, união e probidade administrativa entraram em falência. A Cooperativa Agrícola de Cotia, fundada em 1927, considerado símbolo do cooperativismo no país se autodissolvia em 30/9/1994. Outra gigante, a Cooperativa Central Agrícola Sul Brasil, fundada em 1929, se autodissolveu em 30/ 3/1994. O Banco América do Sul Ltda. fundado em 1/10/1940 foi adquirida pelo Banco Sudameris em 19/6/1998 (TSUNODA, 1985; TOYAMA, 2009). Contribuíram 
para essa queda, o excesso de autoconfiança, a péssima administração, a incapacidade de perceber as sinergias das mudanças e as políticas nacionais.

Em 2008, quando foi comemorado o bicentenário da imigração japonesa no Brasil, a participação dos descendentes japoneses, com o rápido processo de assimilação na sociedade brasileira, os sobrenomes japoneses e a participação relativa nas atividades econômicas foi confundida no contexto nacional decorrente da diluição. Ficará, contudo, a cultura representada pelas comidas japonesas com as adaptações, os esportes, as artes, a religião e o espírito de gestão empresarial.

Dessa forma, para que a presença japonesa no País não seja perdida ao longo do tempo, uma nova modalidade de cooperação precisa ser desenhada, que seja benéfica para ambos os países. Essa nova cooperação deve estar baseada na migração do conhecimento e de capitais japoneses viabilizando atividades produtivas e ambientais na região amazônica.

O episódio do registro do nome "cupuaçu" como marca registrada para várias classes de produtos (incluindo chocolate) no Japão, na União Europeia e nos Estados Unidos pela Asahi Foods Co. Ltd. que foi cancelada no dia 1/3/2004, pelo Escritório de Marcas do Japão (JPO) em Tóquio, cuja ação foi impetrada pelo Grupo de Trabalho Amazônico (GTA), Amazonlink, APA Flora e outros, protocolada em 20 de março de 2003, só tende a envergonhar os imigrantes e seus descendentes e não pode seguir essa lógica no futuro. A Amazônia constitui um tema sensível para os brasileiros, desde os primórdios de sua ocupação, tanto que o caso do cupuaçu mobilizou a opinião pública nacional, levando o Presidente Luiz Inácio Lula da Silva, a sancionar a Lei n. ${ }^{\circ} 11.675$, de 19 de maio de 2008, designando o cupuaçu sendo fruta nacional (HOMMA, 2003).

A cooperação técnica japonesa na Amazônia é bastante antiga, tendo iniciado em 1963, com o Instituto de Pesquisa e Experimentação Agropecuária do Norte (Ipean), visando apoiar os colonos japoneses estabelecidos na Amazônia. A preocupação do governo japonês com os produtores japoneses, abalados com a crise da doença nos pimentais, traduziu-se com a instalação do Instituto Experimental Agrícola Tropical da Amazônia (Inatam), fundado em 1974, e reinaugurado com a presença do ministro da Agricultura, Alysson Paulinelli, em 5 de novembro de 1977. O alto custo da manutenção do Inatam e da presença exclusiva de pesquisadores japoneses levou ao fechamento da instituição e a entrega das instalações para a Embrapa no final da década de 1980, sem condições de sua manutenção.

128 Somanlu, ano 9, n. 1, jan./jun. 2009 
Outros convênios se seguiram, mas os resultados foram pouco promissores, levando ao encerramento das atividades na Embrapa Amazônia Oriental em 2003. As bolsas de estudos de curto e de longo prazo para estudos no Japão, sempre constituíram em atrativos, inclusive com a criação de Associações dos Bolsistas da Jica em diversas capitais, Associação dos Bolsistas do Governo Japonês e Associação Brasileira de ExBolsistas no Japão, entre as principais e denotam o interesse dos descendentes de japoneses e de brasileiros no treinamento recebido e adaptação cultural. Uma avaliação mais aprofundada precisa ser efetuada sobre estes treinamentos, no qual, os de longo prazo, para mestrado e doutorado são os que efetivamente deixaram contribuições efetivas.

Todos estes aspectos ensejam um novo modelo de cooperação nipo-brasileira para a Amazônia. Não se quer com este texto esgotar o assunto, mas os pressupostos básicos que precisam ser considerados dizem respeito aos seguintes tópicos:

- a cooperação nipo-brasileira não pode vislumbrar o lucro imediato se quer atuar em longo prazo. Propostas unilaterais têm a exata duração dos convênios a serem assinados, uma vez que os benefícios precisam ser mútuos. O respeito à soberania amazônica, tema muito sensível para as populações regionais, no qual a cobiça internacional sempre esteve ameaçada e a população regional e os brasileiros colocam em alto grau qualquer tentativa de usurpação nesse sentido, desde os tempos de Brasil colônia, no século XVI;

- as cooperações tendem a provocar mudanças nas prioridades internas dos países beneficiados, de tal sorte, que não podem ser aceitas sem uma grande discussão interna;

- a Amazônia não pode ser considerada como simples fonte de matériaprima e de desova para os produtos industrializados japoneses visando atingir o vasto mercado interno nacional;

- o crescimento dos movimentos sociais no País implicam a necessidade de promover uma ampla discussão das propostas de desenvolvimento a serem implementadas na região amazônica;

No que concerne à agricultura, meio ambiente e recursos naturais, os principais tópicos de cooperação de interesse para a sociedade local, na qual a participação japonesa na Amazônia deve ser expressa em termos de ajuda financeira, investimentos produtivos e técnicos especializados, situam-se nos seguintes campos de atuação: 
- utilização parcial das áreas desmatadas na Amazônia que até 2009, representavam aproximadamente duas vezes a superfície do Japão, com atividades produtivas adequadas, para evitar a contínua incorporação de novas áreas;

- recuperação de áreas que não deveriam ter sido desmatadas, tais como margens de rios, áreas montanhosas, pedregosas, interesse da biodiversidade, entre outras, passíveis de aproveitamento econômico, com atividades produtivas adequadas;

- recuperação de áreas que não deveriam ter sido desmatadas, sem possibilidade de aproveitamento econômico, mediante recuperação pela própria natureza ou induzida;

- programas de recuperação de rios da bacia amazônica, tanto a nível nacional, quanto de países vizinhos onde se concentra a maioria das nascentes do rio Amazonas e de seus afluentes, na formação de um condomínio dos países da bacia amazônica. Os dejetos das cidades ao longo da bacia hidrográfica são canalizados para o curso principal do rio Amazonas, com sérias consequências para a flora e a fauna e da qualidade da água;

- programas de recuperação de estoques pesqueiros do rio Amazonas e de seus afluentes e da embocadura com interface com o oceano Atlântico;

- implantação de indústrias integradas de papel, celulose e beneficiamento de madeira e sua industrialização mediante plantios florestais;

- programas integrados de produção de biodiesel a partir de plantas oleaginosas perenes;

- programas integrados de pecuária de alta produtividade, com a recuperação de ecossistemas destruídos;

- nichos específicos (fruticultura, bambu comestível, plantas medicinais, aromáticos, inseticidas naturais etc.).

\section{Conclusões}

O sucesso da colonização japonesa no Brasil decorreu do modelo baseado na introdução de recursos da biodiversidade exógena, numa época na qual era um comportamento normal. Recursos genéticos da Amazônia eram levados para outras partes do Brasil e do mundo e por sua vez os migrantes trouxeram de outros locais

130 Somanlu, ano 9, n. 1, jan./jun. 2009 
para a região. Verificou-se uma rápida aprendizagem das técnicas de cultivo e beneficiamento de juta e pimenta-do-reino pelos agricultores da Amazônia, mesmo na carência de instituições voltadas para assistência técnica e extensão rural. Mostrou que os agricultores brasileiros não são avessos às inovações, quando condições de preços e mercados são favoráveis.

A discussão sobre a destruição da Amazônia, que passou a se acentuar no final da década de 1960, quanto a perda da biodiversidade e, a partir da década de 1990, com o perigo das mudanças climáticas, enfatiza que este modelo de colonização não seria viável nos dias atuais.

A introdução das atividades produtivas pelos imigrantes japoneses e da indução provocada na agricultura regional provocou grandes desmatamentos na Amazônia. A imagem de uma agricultura equilibrada creditada aos imigrantes japoneses e seus descendentes esconde efeitos colaterais de grande destruição dos recursos naturais da Amazônia. Este aspecto é comum para qualquer atividade produtiva na Amazônia, uma vez que não existem atividades sustentáveis.

O novo enfoque de desenvolvimento induzido pelos descendentes dos japoneses está baseado no aproveitamento da biodiversidade local (cupuaçuzeiro, açaizeiro, castanheira-do-pará, puxurizeiro, uxizeiro, bacurizeiro, piquiazeiro, etc.) associado com plantas exóticas introduzidas no passado e outras mais recentes de forma clandestina.

A incapacidade das instituições nacionais em responderem aos anseios da população constitui a mais grave ameaça para a segurança dos empreendimentos agrícolas dos descendentes dos japoneses e do capital japonês investido no País.

O Japão poderia ajudar muito a Amazônia, mediante convênios técnicocientíficos que sejam complementares, na recuperação das áreas degradadas e da fauna pesqueira, controle da poluição dos rios, tecnologia de madeira, aproveitamento dos recursos da biodiversidade na área de cosméticos, fármacos, corantes naturais, entre os principais. Quanto às exportações, há necessidade de equilibrar a balança comercial dos Estados do Amazonas, Pará e Maranhão com o Japão, desfavorecida pelas importações da Zona Franca de Manaus e dos baixos preços dos produtos da natureza que são exportados.

No caso da agricultura em si, o Brasil avançou muito e os japoneses têm pouco a contribuir nessa área, com exceção de alguns nichos específicos, a não ser em maiores investimentos para os produtos agrícolas de exportação, cujos benefícios retornam para os países importadores com produtos de melhor qualidade, menores 
preços e com qualidade ambiental. Dessa forma, a cooperação técnica-científica precisa ser bem específica e planejada, ocupando vácuos nos quais o Brasil apresenta dificuldade, para que uma nova etapa da migração do conbecimento se efetue nas próximas décadas, de forma mútua e colaborativa, para que no bicentenário da imigração japonesa, esteja comemorando uma nova fase de contribuição planetária.

\section{Referências}

AKIMOTO, M. História sucinta do Prodecere Grupo Campo. Brasília: Campo, 2009. 9p. (digitado).

ALVES, R.T. Embrapa Cerrados celebra centenário da imigração japonesa. Cerrados Informa, Planaltina, v. 9, n. 88, p. 2, fev. 2008.

CRUZ, E. Colonização do Pará. Belém, PA: Instituto Nacional de Pesquisas da Amazônia, $1958.178 \mathrm{p}$.

HOMMA, A. K.O. Amazônia: como aproveitar os benefícios da destruição? Estudos Avançados, São Paulo, v. 54, n. 19, p.:115-135, mai./ago, 2005.

- A Extração de Recursos Naturais Renováveis: o Caso do Extrativismo Vegetal na Amazônia. Tese Doutorado -Viçosa, UFV, 1989. 575p.

- A imigraşão japonesa na Amazônia: sua contribuição ao desenvolvimento agrícola. Belém: Embrapa Amazônia Oriental/Fiepa, 2007. 217p.

- História da agricultura na Amazônia: da era pré-colombiana ao terceiro milênio. Brasília: Embrapa Informação Tecnológica, 2003. 274p.

OLIVEIRA, A.U. Agricultura brasileira, transformações recentes. In: ROSS, J. L. S. (org.). Geografia do Brasil. São Paulo: Edusp, 1996. p. 465-546.

TOYAMA, O. Cem anos de águas corridas da comunidade japonesa. São Paulo: AGWM, 2009. 597p.

TSUNODA, F. Biografia de Kunito Miyasaka. São Paulo: Fundação Kunito Miyasaka, 1985.299p.

132 Somanlu, ano 9, n. 1, jan./jun. 2009 

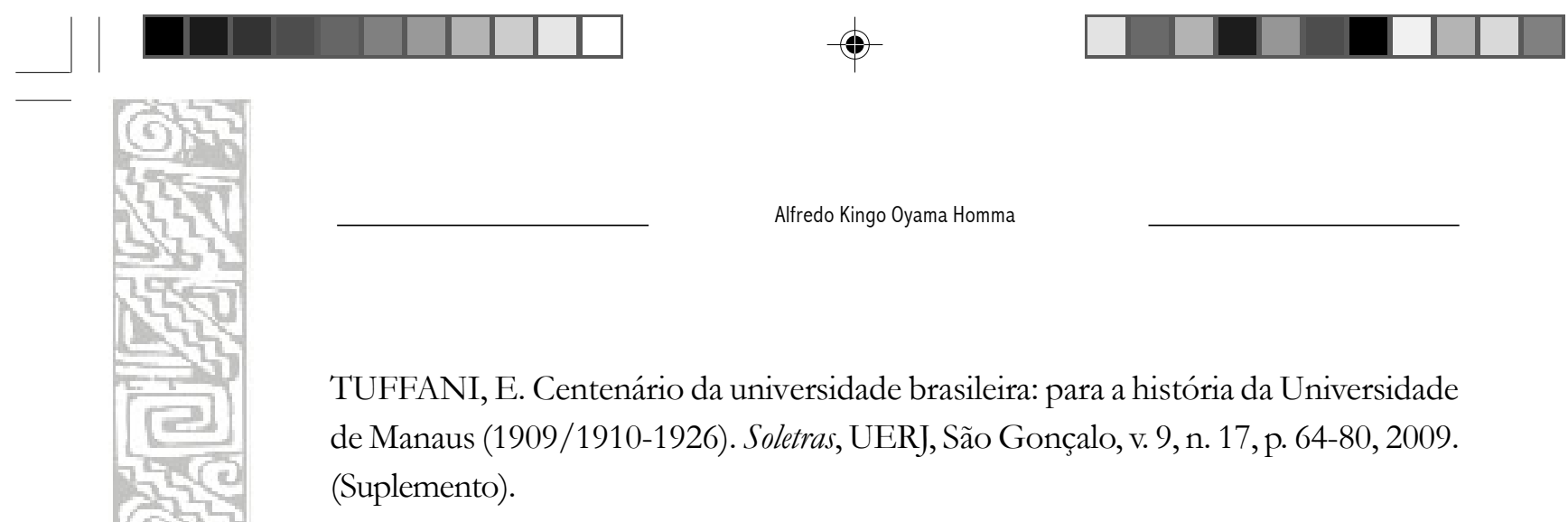
(Suplemento).

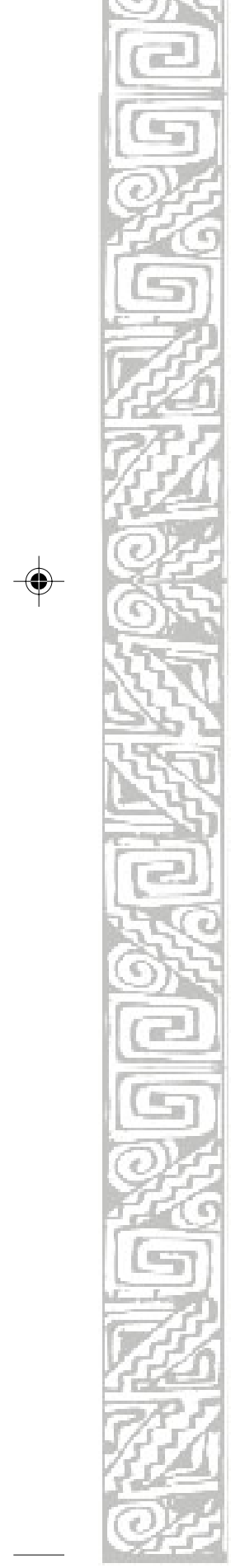

